\title{
Social care and support needs of community-dwelling people with dementia and concurrent visual impairment
}

\begin{abstract}
Objectives: Little is known about the needs of people who have both dementia and visual impairment. This study explored the social care and support needs of people with dementia and concurrent visual impairment, and the barriers and facilitators for meeting these needs. Method: Twenty-six semi-structured interviews were conducted: 21 joint interviews with the person with dementia and visual impairment and their family member / paid carer; and 5 individual interviews with either the person with dementia and visual impairment $(n=4)$ or their family member $(n=1)$. Interviews were audio recorded, transcribed verbatim, and analysed thematically.
\end{abstract}

Results: Three themes are presented. (1) Social care needs: having dementia can reduce an individual's ability to cope with their visual impairment, and in turn make the person more dependent and prone to lack of daily stimulation. (2) Barriers to using technology to meet social care needs: difficulties were reported in learning to use unfamiliar technology, and for some, the presence of dementia made visual impairment aids unusable and vice versa. Visual impairment aids were also perceived as expensive. (3) Familiarity as a facilitator for meeting social care needs: living at home or taking furnishings and ornaments into a new home environment facilitated retention of independence, and continuity of paid carers / volunteers facilitated the caring relationship between the individual and staff / volunteer.

Conclusion: Dementia and visual impairment often coexist and care workers will better serve older people if they are aware of the social care and support needs that arise from having both conditions.

Nyman, S. R., Innes, A., \& Heward, M. (in press). Social care and support needs of community-dwelling people with dementia and concurrent visual impairment. Aging and Mental Health. 
Keywords: General < Dementia and Cognitive Disorders; Social Support < Psychosocial and Cultural Aspects; Caregiving and interventions < Caregiving; comorbidity; vision disorders 


\section{Introduction}

Older people often have more than one chronic health condition (Hughes, McMurdo, \& Guthrie, 2013; Marengoni, Rizzuto, Wang, Winblad, \& Fratiglioni, 2009; Sadanand et al., 2013). The risk of acquiring chronic health conditions increases with age (Jacobs et al., 2012), and some conditions in particular have been associated with comorbidity including dementia (e.g. Alzheimer's disease) (Fox et al., 2014) and visual impairment (e.g. macular degeneration) (Garin et al., 2014). In the UK, estimates suggest that 850,000 people have dementia (Prince et al., 2014), and almost two million people have a visual impairment, of which approximately 360,000 are registered as blind or partially sighted (Access Economics Pty Limited, 2009). The proportion of the older adult population living with both dementia and visual impairment is currently unknown. However, given the high prevalence rates for both conditions singularly, and the ageing of the world population (National Institute on Aging, National Institutes of Health, \& World Health Organization, 2011), it is expected that the numbers of people living with both dementia and visual impairment will become a significant proportion of older people in the future. In addition, some forms of dementia such as Alzheimer's disease and dementia with Lewy Bodies can impair vision (Calderon et al., 2001; Glosser et al., 2002). In particular, people with posterior cortical atrophy often have healthy eyes but have sight loss because the area of the brain that interprets visual images has been affected (Crutch et al., 2012). There is thus a need to ascertain the social care and support needs of people with both dementia and visual impairment.

There is a paucity of literature on care practice for people with dementia and concurrent visual impairment. What is known is that people with dementia are more likely to require assistance with performing activities of daily living and to be in contact with social services (Darbà, Kaskens, \& Lacey, 2014; Lima-Silva et al., 2015). They are also more at risk of depressive symptoms (Kosteniuk et al., 2014) and mortality, with dementia as the sixth

Nyman, S. R., Innes, A., \& Heward, M. (in press). Social care and support needs of community-dwelling people with dementia and concurrent visual impairment. Aging and Mental Health. 
leading cause of death in the United States (Alzheimer's Association, 2014). Similarly, it is known that people with visual impairment often have greater dependency on others due to difficulties with mobility and activities of daily living (Burmedi, Becker, Heyl, Wahl, \& Himmelsbach, 2002; Desrosiers et al., 2009; Ke, Montgomery, Stevenson, O'Neill, \& Chakravarthy, 2007; Nyman, Dibb, Victor, \& Gosney, 2012). People with visual impairment are also more at risk of developing depressive symptoms (Bernabei et al., 2011), reduced cognitive functioning (Garin et al., 2014) and are at higher risk of mortality (Cacciatore et al., 2004). However, few studies have assessed the potential needs that may be unique to people who experience both conditions concurrently.

In our search of the published literature we found one peer-reviewed empirical study on the subject (Lawrence, Murray, Ffytche, \& Banerjee, 2009). In this UK-based study, Lawrence et al. identified a risk-aversive approach to care for people with dementia and visual impairment through qualitative interviews with people living with dementia in their own homes, their family members, and relevant community staff. They found this was due to the following: visual impairment reduced people's ability to safely manage tasks; dementia impaired people's risk perception; family members' safety concerns; low priority among dementia care workers to address low vision; and a lack of training for visual impairment care workers to address dementia-related needs. The authors concluded that more joined-up working was required between the dementia and visual impairment services to better serve people with both conditions.

Given the lack of information on the needs of people with concurrent dementia and visual impairment and the increasing prevalence of both conditions amongst older people (Access Economics Pty Limited, 2009; Prince et al., 2015), this paper explores the social care and support needs of people who have both dementia and visual impairment, and the barriers and facilitators for providing them with effective social care and support.

Nyman, S. R., Innes, A., \& Heward, M. (in press). Social care and support needs of community-dwelling people with dementia and concurrent visual impairment. Aging and Mental Health. 


\section{Methods}

\section{Design}

Face-to-face semi-structured interviews were conducted with people with dementia and concurrent visual impairment and their family member or paid carer. The interview questions centred on the lived experience of having both dementia and visual impairment, the level of social care and support that was being received and any unmet needs, and the factors that might facilitate, or act as barriers to, receiving the social care and support they needed (see the online supplementary material for the interview schedule). Prior to commencement, this study was approved by the Social Care Research Ethics Committee (Ref: 12/IEC08/0040). Interviews were conducted at three research sites representing the northern, middle, and southern parts of England. Purposive sampling across three sites was also used because of the anticipated difficulty with recruitment. Recruitment was conducted between March and November 2013. Funding was provided for recruitment of up to 30 participants (10 per site), and 26 interviews were conducted within this timeframe (8-9 per site).

\section{Participants}

Local organisations and service providers were requested to contact their distribution lists to inform their members of the project and to ask those interested and eligible to contact the research team. Organisations included those from the third sector that work with people with dementia, people with a visual impairment, and other organisations involved in the provision of social care for older people. Those that expressed an interest in the study were screened to confirm eligibility by telephone and posted an information sheet and consent form. After at least a week to consider taking part in the study, participants that volunteered to continue were then contacted to arrange a mutual time for the interview at their home address. Participants were offered the option of having a family member or paid carer present and

Nyman, S. R., Innes, A., \& Heward, M. (in press). Social care and support needs of community-dwelling people with dementia and concurrent visual impairment. Aging and Mental Health. 
most preferred having someone with them who also participated in the interview. All types of dementia and visual impairment were considered eligible for our sample, as were different types of housing within the community (see Table 1 for study inclusion and exclusion criteria). Participants who had additional health conditions were not excluded given the high likelihood of comorbidity in this population (Fox et al., 2014; Garin et al., 2014). No inclusion / exclusion criteria were used for family members or paid carers as they were invited to attend by the person with dementia and concurrent visual impairment.

[Table 1 near here]

\section{Procedure}

Before each interview was conducted informed consent was obtained by the researcher. The researcher discussed the information sheet with each participant / dyad, giving them an opportunity to ask any questions and a consent form was then signed by each participant (separately for family members / paid carers where applicable). The interview schedule was then followed and each interview lasted approximately one hour. The researcher followed process consent, whereby consent provided at the beginning of the interview was not assumed to ensure consent for the full duration of the interview (Dewing, 2002; 2007). The researcher paid close attention to the comments and non-verbal communication of the person with dementia and if they appeared to become uncomfortable with the interview or unsure of the purpose of the conversation, then informed consent was verbally repeated. Each interview was audio recorded using a digital Dictaphone and transcribed verbatim. Field notes were also kept by the researchers to supplement the transcripts. While three recruitment sites were used for data collection, the data analysis was conducted by a research team at one site.

Nyman, S. R., Innes, A., \& Heward, M. (in press). Social care and support needs of community-dwelling people with dementia and concurrent visual impairment. Aging and Mental Health. 


\section{Analysis}

The interview transcripts were analysed thematically using NVivo.10 software (Joffe \& Yardley, 2004). The unit of coding was each meaningful phrase, so that relevant utterances could be coded flexibly and vary in length (e.g. rather than coding line by line separately). Coding was conducted manifestly (rather than latent coding of underlying meanings) and inclusively (utterances can be flexibly coded into more than one code). The analysis was inductive, in that themes were allowed to emerge from the transcripts as the analysis progressed, rather than imposing a theoretical framework to the data. However, we did deductively impose the following overall framework to ensure the analysis directly addressed the five aims and objectives of the project: 1) social care needs for persons with dementia and visual impairment, 2) social care needs of family members, 3) current models of social care and support, and 4) barriers and 5) facilitators to providing high quality, cost effective social care and support.

A coding frame was developed by one researcher, checked by a second, and verified by a third. To enhance the rigour of the analysis, after three interviews were analysed, the analysis process and emergent themes were scrutinised by the wider project team. This included social science researchers from the two other recruitment sites, and a colleague from a third sector organisation for people with visual impairment. Once the analysis was completed in full, a report was then scrutinised by the same colleagues, who were invited to make any critical comments independent from the team conducting the analysis. In addition, feedback was also obtained from a non-academic audience at an event hosted by the project team, where the views of people with dementia, visual impairment, and those working with these groups were solicited. Composite vignettes were created to prompt discussion around the themes that emerged from the analysis, and the critical comments solicited from this event were taken on board in the interpretation of the findings.

Nyman, S. R., Innes, A., \& Heward, M. (in press). Social care and support needs of community-dwelling people with dementia and concurrent visual impairment. Aging and Mental Health. 
This paper reports on the findings that emerged as a result of the unique combination of having both dementia and visual impairment. Some of the comments made by participants reflected findings that have already been addressed in the literature. For example, interviewees confirmed earlier findings about the trauma of receiving a diagnosis of dementia (Aminzadeh, Byszewski, Molnar, \& Eisner, 2007) or visual impairment (Nyman et al., 2012), and that help and support from relatives and neighbours is appreciated both by people with dementia (Kelly \& Innes, 2014; Wenger, Scott, \& Seddon, 2002) and those with visual impairment (Nyman et al., 2012). To avoid duplication and make a novel contribution to the literature, we only present here the three emergent themes that specifically related to concurrent dementia and visual impairment: Social care needs, barriers that impeded the potential for technology to meet social care needs, and familiarity as a facilitator for meeting social care needs.

Nyman, S. R., Innes, A., \& Heward, M. (in press). Social care and support needs of community-dwelling people with dementia and concurrent visual impairment. Aging and Mental Health. 


\section{Findings}

Twenty-six interviews were conducted, of which 21 were joint interviews and 5 individual interviews. Each joint interview was with a community-dwelling person with dementia and visual impairment and either a family member - their spouse $(n=12 ; 5$ wives aged $68-84$ and 7 husbands aged 64-86) or relative ( $n=2$, both female) - or paid member of care staff from an extra care scheme or local service provider $(n=7)$. The remaining five interviews were either solely with the person with dementia and visual impairment $(n=4)$ or their relative on behalf of the participant $(n=1)$. The age of people with dementia and visual impairment ranged from 58 to 96 years $($ mean $=82.1)$, and two thirds were female. Half of the participants had macular degeneration as the lead cause of visual impairment, which could be in part because we recruited from members of the national charity, the Macular Disease Society (see Table 2).

[Table 2 near here]

\section{Social care needs of individuals with dementia and visual impairment}

Social needs were highlighted from having the combination of dementia and visual impairment. One participant aged 77 had lived well with visual impairment for decades. However, it was only more recently when he developed Alzheimer's disease that he began to become dependent on others, as commented by his wife:

...So it's only in the later years and certainly since Alzheimer's was diagnosed that the eyesight is...I think it's a case of the sight and the brain not working together. He's really troubled with his sight, $m m$... Yes, but he managed it quite well until he was diagnosed with Alzheimer's, mm (B6C).

This example suggests that the presence of dementia in addition to visual impairment can

Nyman, S. R., Innes, A., \& Heward, M. (in press). Social care and support needs of community-dwelling people with dementia and concurrent visual impairment. Aging and Mental Health. 
exacerbate existing difficulties and lead to greater dependence. This was echoed by another family member who commented on his wife aged 67 who had posterior cortical atrophy. At the time of interview, the participant did not have memory problems but had developed significant visual problems and was registered partially sighted. The family member commented on the importance of keeping his spouse active, and in particular physically active, with her visual impairment. He had noticed that her ability to use her vision was deteriorating and that she had to rely more and more on memory for her independence: ...she couldn't find her way home, that's the situation we're in. As long as it's a familiar route with a...but if she deviates off even going down the road she's lost her way around the corner...It's learnt, and make no mistakes, because once the mistakes made... and that's evolving now, where six months ago that...locally, that wouldn't have happened, probably (B7C).

Although this couple were currently satisfied with their living standards and lifestyle, the family member in particular raised concerns about the future and for how long his wife could remain independent when her ability to rely on her memory will become increasingly limited.

Lack of daily stimulation was raised by some participants. For example, a woman aged 83 with dementia and visual impairment was immobile and needed her husband to push her in a wheelchair. This participant commented on her boredom when her husband was busy with other activities:

He just takes me away out round the shops, pretending that I'm going cooking, and all the rest of it, and it's nice to get back indoors. I find the young people are a little bit overpowering, aren't they?...But it's nice while it's there, and then you can go...[hah...] ... and have a cup of coffee... But I grumble because I'm on my own when he's in the garden, and then it all swings round the other way, doesn't it, and you

Nyman, S. R., Innes, A., \& Heward, M. (in press). Social care and support needs of community-dwelling people with dementia and concurrent visual impairment. Aging and Mental Health. 
know...nobody speaks to me, and...yes, they do. Oh you get grumpy. Can't help it (B5PWD).

Solutions to keeping individuals with dementia and visual impairment stimulated in daily activity were not necessarily forthcoming. One participant had missed social occasions because they had forgotten when they were scheduled, another participant could not participate in a Scrabble (board game) club because they could no longer concentrate well enough to play the game, and another participant had hearing loss that impaired his ability to socialise in groups because he could not follow the conversation. Previously held hobbies such as reading and watching television were also abandoned by another participant because they could no longer follow the plot in the book / programme due to their visual impairment (can no longer perceive words on the page or images on the screen) and dementia (impaired short-term memory to follow the narrative portrayed).

\section{Barriers to the potential for technology to meet social care needs}

The participants in our study talked about making use of a wide range of equipment in and outside the home, including assistive technology, devices to aid mobility, and devices specifically to make use of residual vision. However, several barriers were identified in using technology. Learning to use new aids and appliances proved problematic for some. For example, a family member commented that his wife aged 83 with dementia and visual impairment initially found difficulty in using a newly fitted stair lift. She had to get used to keeping her feet on the foot rest and her hand on the catch to make the chair move up or down the stairs. Another participant, aged 82, who lives with her adult daughter who is blind described her difficulty in using a new cooker:

I mean, I can use a microwave with no problem. I've got a new cooker which at the moment is driving me mad and I think that's half to do with my memory plus my

Nyman, S. R., Innes, A., \& Heward, M. (in press). Social care and support needs of community-dwelling people with dementia and concurrent visual impairment. Aging and Mental Health. 
eyesight. I mean, it's stupid, my daughter who can't see at all, has to come out and turn the oven on for me. We have to turn this on and then do that and do something else. I don't know why I chose this stupid cooker. I'm sure there are easier ones. I mean, I'm getting better at it now, but it makes me cross...(B8PWD).

Some aids were not usable because of the dual impairment of dementia and visual impairment. Examples were given where memory aids were not usable because of visual impairment. Similarly, visual impairment aids were not usable because of dementia. For memory aids, an adult daughter of a man aged 86 highlighted that these devices rely on an individual's vision to serve as a reminder function:

But with Pops you see, his sight, he hasn't got that visual has he, that visual aid to react to his memory, to kick in that memory.... With Dad, even if he had something like a switch on the wall in places like this that told him what day it was, by the time he got to the door he'd've forgotten, so that is another difficult thing that, you know, it's so difficult to actually stimulate the brain and the memory, because of the lack of sight... Because we'll be asked the same question, two minutes later, all through Saturday won't we? And it's, you have to answer exactly the same way you answered it before, as if it was never asked.... (WC3)

For visual impairment aids, these rely on short-term memory for comprehension and retention of information. A family member commented that her husband aged 93 found great difficulty in using a closed-circuit television (CCTV); a magnifier that projects an image on to a television screen to e.g. help read a newspaper:

Yes, he tried these things with screens that come up with... and you have huge print on it. He tried that for a little while but it was so difficult for him, it gave him a headache. Because the words, you had to get the letters so big so that he could see the, but then he had to work out what... and put it all together, if you know what I

Nyman, S. R., Innes, A., \& Heward, M. (in press). Social care and support needs of community-dwelling people with dementia and concurrent visual impairment. Aging and Mental Health. 
mean, in his mind....To be able to string together what it was talking about on there. But he was so concentrating on each letter, he couldn't really think about what it was about, in the end $(B 9 C)$.

Another family member also reported purchasing a CCTV and her spouse found it unusable. However, another participant with relatively milder memory difficulty was able to use her CCTV and said that it was her 'lifeline' to still be able to read. Both commented on the expense of CCTVs at circa $£ 2,000$. Indeed, visual impairment aids were generally felt to be expensive and this was perceived as another barrier to acquiring such devices.

\section{Familiarity as a facilitator for meeting social care needs}

Familiarity was raised as a facilitator for retaining independence, feeling at home in a new care environment, and for building relationships with paid carers. A participant aged 85 reflected on the importance of remaining in her own home and being familiar with the environment she was living in for her independence. This is particularly important for people with visual impairment so that they can keep furniture and items in the same locations to aid navigation and finding objects:

...because once you've been in it, you've been in it for so many years, you know where everything is practically, don't you? You get used to what you're doing and how you're doing it.... So really I don't need it. I try not to put people about having to do this, that and the other for me because I don't like it. I don't like being carried about. I like to be able to do it myself(Y3PWD).

For a man who had moved into a flat in an extra care housing unit, he described how he was sorry to leave his home but appreciated that he was now 'a menace to himself' and could no longer safely live alone. What seemed to ease the transition to living in his new flat was some

Nyman, S. R., Innes, A., \& Heward, M. (in press). Social care and support needs of community-dwelling people with dementia and concurrent visual impairment. Aging and Mental Health. 
sense of familiarity and continuity with his old home environment. He commented that his flat felt homely because he was able to bring his own furnishings and ornaments with him:

This is all my own furniture.... Oh, yes, it is. I mean, I'm surprised how much space there is. And, I mean, I've got pictures everywhere. Yes, it's...I, I like the place very much in here, I'm perfectly happy here (W4PWD).

Comments were made about the relationships between the individual with dementia and visual impairment and paid carers. Consistency in having the same carer provide care was highlighted as particularly helpful. A daughter, who does not live with her father who is now living in a flat in an extra care housing unit, spoke of the rapport that has been built between her father and the staff who work at the facility, and also with herself. This consistency in who was providing care was echoed by a family member living in his own home with his wife aged 85 . He had volunteers visit the house each week that acted as both a befriending service for his wife and respite for him. In contrast, when the family member commented on formal care from social services, he explained that the turnover of staff made it difficult for his wife to relate to the paid carers:

She doesn't relate to them at all, and the, one of the problems is that erm, every time we get to know one she's replaced [paid carer]...An assessment was done and I can't see... Oh yes. Er, [name of paid carer], she was a nice girl. Then somebody called [name of paid carer] came along erm, er, and then we're two years on we get the occupational therapist people coming in. Erm, and then [name of paid carer], er, another person. You see...you see one person for one time, and to me care is, is continuous. It isn't...one person looking in and saying are you alright and ticking a $\operatorname{box}(Y 5 C)$.

Nyman, S. R., Innes, A., \& Heward, M. (in press). Social care and support needs of community-dwelling people with dementia and concurrent visual impairment. Aging and Mental Health. 


\section{Discussion}

This study aimed to explore the social care and support needs of people with dementia and concurrent visual impairment, and the barriers and facilitators for providing them with effective social care and support. For social care needs, the above examples illustrated how dementia can reduce an individual's ability to cope with their visual impairment, and in turn make them more dependent and more prone to lack of daily stimulation. Taken together, the combination of dementia and visual impairment can be a particular threat to the individual's quality of life. For barriers to the use of technology to meet social care needs, difficulties were reported in learning to use unfamiliar technology, the presence of dementia symptoms making visual impairment aids unusable and vice versa, and the expense of visual impairment aids. For familiarity as a facilitator to meeting social care needs, having a familiar living environment facilitated independence, and continuity of paid carers / volunteers facilitated caring relationships.

Our findings suggest that dementia and concurrent visual impairment can exacerbate the difficulties of living with each condition separately, and therefore further reduce an individual's ability to remain independent and carry out activities of daily living. Similar findings were reported in an earlier study, which also reported a low priority among dementia care workers to address low vision, and a lack of training for visual impairment care workers to address dementia-related needs (Lawrence et al., 2009). This suggests that to improve social care and support, more attention to the needs of those with visual impairment is required among dementia care workers and vice versa among visual impairment care workers. This would further recent work that has produced guidelines on the design of homes and living spaces for people with dementia and visual impairment (Greasley-Adams, Bowes, Dawson, \& McCabe, 2014). In addition, in the UK, a new Dementia Eye Care Pathway has been proposed that would promote early and ongoing visual health assessment of people with

Nyman, S. R., Innes, A., \& Heward, M. (in press). Social care and support needs of community-dwelling people with dementia and concurrent visual impairment. Aging and Mental Health. 
dementia (Hancock, Shah, Edgar \& Bowen, 2015). Such a pathway would be welcome as it includes timely provision of information to people with dementia and their family members, facilitation of access to optometric and ophthalmic services, and additional subsidies for the purchase of spectacles.

Having dementia and concurrent visual impairment posed challenges for some individuals to remain stimulated each day. This supports earlier work that has identified people with visual impairment are at risk of reduced participation in daily activities and withdrawal of social roles (Desrosiers et al., 2009). Because needs will vary among individuals, there is broad consensus on the use of a person-centred approach, which places the individual and their family member's needs and preferences at the heart of all care provision (Edvardsson, Winblad, \& Sandman, 2008; National Institute for Health and Clinical Excellence, 2006). Thus, the solution to engaging people with dementia and concurrent visual impairment in daily meaningful activity will depend on the interests and capabilities of the individual and where applicable their family member.

Our findings suggest that some people with dementia and concurrent visual impairment may have particular difficulty in learning to use new aids and appliances. In addition, visual impairment may reduce an individual's ability to use memory aids, and dementia may inhibit one's ability to use aids for visual impairment due to impaired shortterm memory. Designers of assistive devices are required to work with people with dementia and sight loss to find novel solutions to these challenges. For example, memory aids may be developed that provide audio cues. Such technology exists for those with visual impairment but they are not necessarily effective. For example, at the press of a button, a talking clock can provide an audio message to remind someone of the time and date. However, such devices often do not have the appearance that resembles a clock a sighted person would use, and so may not be readily used by a person with dementia. Some visual impairment aids such community-dwelling people with dementia and concurrent visual impairment. Aging and Mental Health. 
as CCTV may need to have more user-friendly interfaces before they can be readily used by people with dementia. Also, the introduction of any new technology for the benefit of people with dementia and concurrent visual impairment should be implemented as early as possible within the home to facilitate learning. Additional training may also be required to help the individual adopt the use of technology into daily routines. The findings from the current study supports earlier work conducted with other population groups. For example, a recent UK study explored the use of memory aids for older people living in supported accommodation. With a sample of mainly cognitively intact older adults, there was difficultly with matching aids to needs, resistance to trialling aids, and user difficulty due to the complexity of using electronic aids (Collerton, Forster, \& Packham, 2014).

Our findings suggest that having a familiar living environment was important to participants. Living at home served to maintain independence as individuals had control over their environment and knew where to find items they needed for everyday living. This was also found to be the case when furnishings and ornaments were allowed to be taken into a new residence such as extra care housing, which may also facilitate wellbeing by helping people to age in place (Peace, Holland, \& Kellaher, 2006). Familiarity of care workers and volunteers was also raised by participants in this study. This enabled participants to develop rapport and build relationships with staff and volunteers. This finding contradicts earlier work that suggested continuity of care did not necessarily mean seeing the same person, but good quality information and support, and coordination between services (Parker, Corden, \& Heaton, 2011). However, if possible, having the same member of staff or volunteer visit someone in their home could help establish better rapport and trust with the person receiving care.

Nyman, S. R., Innes, A., \& Heward, M. (in press). Social care and support needs of community-dwelling people with dementia and concurrent visual impairment. Aging and Mental Health. 


\section{Limitations / ideas for future research}

This study used interviews to consult with an under-researched subgroup of the older population. A strength of the study was that recruitment was conducted across three different sites and so the findings are not specific to a particular area. However, it is acknowledged that the sample was predominantly Caucasian. Other barriers and facilitators among people with dementia and concurrent visual impairment may be raised by members of ethnic minorities. Similarly, this study was only concerned with community-dwelling older people, and different challenges and opportunities for supporting and caring for people may present themselves to care staff working in hospitals and care home settings. In addition, we included participants with other health conditions (e.g. hearing impairment) due to the high likelihood of comorbidity among this population. However, the presence of other conditions may have influenced the findings such as eliciting more comments about reduced independence and ability to engage in leisure activities. Further research might explore the relationship between other conditions (e.g. dementia and hearing loss) and which health conditions impact most on daily living among people with multiple health conditions.

Lastly, this study was necessarily qualitative and exploratory in nature. A future prospective longitudinal study could investigate the development of dementia and concurrent visual impairment among individuals and the effects on quality of life. For example, the prevalence and impact of the chronological order of development of conditions may hold significance. Indeed, it may be that individuals who have had visual impairment first and then later acquired dementia may be more prevalent; although the reverse may be associated with greater care needs, depending on severity and speed of deterioration.

Nyman, S. R., Innes, A., \& Heward, M. (in press). Social care and support needs of community-dwelling people with dementia and concurrent visual impairment. Aging and Mental Health. 


\section{Conclusion}

This study has highlighted the unique social care and support needs of people with dementia and concurrent visual impairment. It has also highlighted the potential barriers to using technology and potential facilitators for meeting social care and support needs. To provide person-centred and effective care for individuals, and to better support family members, it is important that professionals working in the dementia field are familiar with the needs of people with visual impairment, and that professionals working as visual impairment specialists become familiar with the needs of people with dementia. Training opportunities and joint working would help facilitate shared learning.

Nyman, S. R., Innes, A., \& Heward, M. (in press). Social care and support needs of community-dwelling people with dementia and concurrent visual impairment. Aging and Mental Health. 


\section{References}

Access Economics Pty Limited. (2009). Future sight loss UK (1): The economic impact of partial sight and blindness in the UK adult population. London: Royal National Institute of Blind People.

Alzheimer's Association. (2014). 2014 Alzheimer's disease facts and figures. Alzheimer's and Dementia, 10, e47-e92.

Aminzadeh, F., Byszewski, A., Molnar, F. J., \& Eisner, M. (2007). Emotional impact of dementia diagnosis: Exploring persons with dementia and caregivers' perspectives. Aging \& Mental Health, 11, 281-290.

Bernabei, V., Morini, V., Moretti, F., Marchiori, A., Ferrari, B., Dalmonte, E. et al. (2011). Vision and hearing impairments are associated with depressive-anxiety syndrome in Italian elderly. Aging \& Mental Health, 15, 467-474.

Burmedi, D., Becker, S., Heyl, V., Wahl, H.-W., \& Himmelsbach, I. (2002). Behavioral consequences of age-related low vision. Visual Impairment Research, 4, 15-45.

Cacciatore, F., Abete, P., Maggi, S., Luchetti, G., Calabrese, C., Viati, L. et al. (2004). Disability and 6-year mortality in elderly population. Role of visual impairment. Aging Clinical and Experimental Research, 16, 382-388.

Calderon, J., Perry, R. J., Erzinclioglu, S. W., Berrios, G. E., Dening, T. R., \& Hodges, J. R. (2001). Perception, attention, and working memory are disproportionately impaired in dementia with Lewy bodies compared with Alzheimer's disease. Journal of Neurology, Neurosurgery, and Psychiatry, 70 (2), 157-164.

Nyman, S. R., Innes, A., \& Heward, M. (in press). Social care and support needs of community-dwelling people with dementia and concurrent visual impairment. Aging and Mental Health. 
Collerton, D., Forster, E., \& Packham, D. (2014). An exploratory study of the effectiveness of memory aids for older people living in supported accommodation. Journal of Applied Gerontology, 33, 963-981.

Crutch, S. J., Lehmann, M., Schott, J. M., Rabinovici, G. D., Rossor, M. N., \& Fox, N. C. (2012). Posterior cortical atrophy. Lancet Neurology, 11 (2), 170-178.

Darbà, J., Kaskens, L., \& Lacey, L. (2014). Relationship between global severity of patients with Alzheimer's disease and costs of care in Spain; results from the co-dependence study in Spain. European Journal of Health Economics, Published online 28 October, DOI: 10.1007/s10198-014-0642-0.

Desrosiers, J., Wanet-Defalque, M.-C., Témisjian, K., Gresset, J., Dubois, M.-F., Renaud, J. et al. (2009). Participation in daily activities and social roles of older adults with visual impairment. Disability and Rehabilitation, 31, 1227-1234.

Dewing, J. (2002). From ritual to relationship: A person-centred approach to consent in qualitative research with older people who have a dementia. Dementia, 1, 157-171.

Dewing, J. (2007). Participatory research: A method for process consent with persons who have dementia. Dementia, 6, 11-25.

Edvardsson, D., Winblad, B., \& Sandman, P. (2008). Person-centred care of people with severe Alzheimer's disease: current status and ways forward. Lancet Neurology, 7, $362-367$.

Fox, C., Smith, T., Maidment, I., Hebding, J., Madzima, T., Cheater, F. et al. (2014). The importance of detecting and managing comorbidities in people with dementia? Age and Ageing, 43, 741-743.

Nyman, S. R., Innes, A., \& Heward, M. (in press). Social care and support needs of community-dwelling people with dementia and concurrent visual impairment. Aging and Mental Health. 
Garin, N., Olaya, B., Lara, E., Moneta, M. V., Miret, M., Ayuso-Mateos, J. L. et al. (2014). Visual impairment and multimorbidity in a representative sample of the Spanish population. BMC Public Health, 14, e815.

Glosser, G., Gallo, J., Duda, N., de Vries, J. J., Clark, C. M., \& Grossman, M. (2002). Visual perceptual functions predict instrumental activities of daily living in patients with dementia. Neuropsychiatry, Neuropsychology, and Behavioral Neurology, 15 (3),198206.

Greasley-Adams, C., Bowes, A., Dawson, A., \& McCabe, L. (2014). Good practice in the design of homes and living spaces for people with dementia and sight loss. Stirling, UK: Dementia Services Development Centre. Available online: http://dementia.stir.ac.uk/system/files/filedepot/12/good_practice_in_the_design_of h omes_and_living_spaces_for_people_living_with_dementia_and_sight_loss_final.pdf [accessed 09/11/2015].

Hancock, B., Shah, R., Edgar, D. F., \& Bowen, M. (2015). A proposal for a UK dementia eye care pathway. Optometry in Practice, 16 (2), 71-76.

Hughes, L. D., McMurdo, M. E. T., \& Guthrie, B. (2013). Guidelines for people not for diseases: The challenges of applying UK clinical guidelines to people with multimorbidity. Age and Ageing, 42, 62-69.

Jacobs, J. M., Maaravi, Y., Cohen, A., Bursztyn, M., Ein-Mor, E., \& Stessman, J. (2012). Changing profile of health and function from age 70 to 85 years. Gerontology, 58, 313-321.

Nyman, S. R., Innes, A., \& Heward, M. (in press). Social care and support needs of community-dwelling people with dementia and concurrent visual impairment. Aging and Mental Health. 
Joffe, H., \& Yardley, L. (2004). Content and thematic analysis. In D. F. Marks \& L. Yardley (Eds.), Research methods for clinical and health psychology (pp. 56-68). London: Sage.

Ke, K. M., Montgomery, A.-M., Stevenson, M., O'Neill, C., \& Chakravarthy, U. (2007). Formal and informal care utilisation amongst elderly persons with visual impairment. British Journal of Ophthalmology, 91, 1279-1281.

Kelly, F., \& Innes, A. (2014). Facilitating independence: The benefits of a post-diagnostic support project for people with dementia. Dementia, Published online 17 February, DOI: $10.1177 / 1471301214520780$.

Kerssens, C., Kumar, R., Adams, A. E., Knott, CC., Matalenas, L., Sanford, J. A. et al. (2015). Personalized technology to support older adults with and without cognitive impairment living at home. American Journal of Alzheimer's Disease and Other Dementias, 30, 85-97.

Kosteniuk, J. G., Morgan, D. G., O'Connell, M. E., Crossley, M., Kirk, A., Stewart, N. J. et al. (2014). Prevalence and covariates of elevated depressive symptoms in rural memory clinic patients with mild cognitive impairment or dementia. Dementia and Geriatric Cognitive Disorders Extra, 4, 209-220.

Lawrence, V., Murray, J., Ffytche, D., \& Banerjee, S. (2009). "Out of sight, out of mind": A qualitative study of visual impairment and dementia from three perspectives. International Psychogeriatrics, 21, 511-518.

Lima-Silva, T. B., Bahia, V. S., Carvalho, V. A., Guimarães, H. C., Caramelli, P., Balthazar, M. L. et al. (2015). Direct and indirect assessments of activities of daily living in

Nyman, S. R., Innes, A., \& Heward, M. (in press). Social care and support needs of community-dwelling people with dementia and concurrent visual impairment. Aging and Mental Health. 
behavioral variant frontotemporal dementia and Alzheimer disease. Journal of Geriatric Psychiatry and Neurology, 28, 19-26.

Marengoni, A., Rizzuto, D., Wang, H. X., Winblad, B., \& Fratiglioni, L. (2009). Patterns of chronic multimorbidity in the elderly population. Journal of the American Geriatrics Society, 57, 225-230.

Mental Capacity Act. (2005). Office of public sector information. London: The Staionary Office Limited. Retrieved online on 01/06/2015 from: www.legislation.gov.uk/ukpga/2005/9/contents.

National Institute for Health and Clinical Excellence. (2006). Dementia: Supporting people with dementia and their carers in health and social care. NICE clinical guidline 42 Manchester, UK: National Institute for Health and Clinical Excellence.

National Institute on Aging, National Institutes of Health, \& World Health Organization (2011). Global health and aging. Bethesda, MD: National Institute on Aging, National Institutes of Health, \& World Health Organization.

Nyman, S. R., Dibb, B., Victor, C. R., \& Gosney, M. A. (2012). Emotional well-being and adjustment to vision loss in later life: A meta-synthesis of qualitative studies. Disability and Rehabilitation, 34, 971-981.

Parker, G., Corden, A., \& Heaton, J. (2011). Experiences of and influences on continuity of care for service users and carers: Synthesis of evidence from a research programme. Health and Social Care in the Community, 19, 576-601.

Peace, S., Holland, C., \& Kellaher, L. (2006). Environment and identity in later life. Maidenhead, UK: Open University Press.

Nyman, S. R., Innes, A., \& Heward, M. (in press). Social care and support needs of community-dwelling people with dementia and concurrent visual impairment. Aging and Mental Health. 
Prince, M., Knapp, M., Guerchet, M., McCrone, P., Prina, M., Comas-Herrera, A. et al. (2014). Dementia UK: Update (second edition). London: Alzheimer's Society.

Prince, M., Wimo, A., Guerchet, M., Ali, G.-C., Wu, Y.-T, \& Prina, M. (2015). World Alzheimer report 2015. The global impact of dementia: An analysis of pravalence, incidence, cost and trends. London: Alzheimer's Disease International.

Sadanand, S., Shivakumar, P., Girish, N., Loganathan, S., Bagepally, B. S., Kota, L. N. et al. (2013). Identifying elders with neuropsychiatric problems in a clinical setting. Journal of Neurosciences in Rural Practice, 4, S24-S30.

Tak, S. H., Beck, C., \& Hong, S. H. (2013). Feasibility of providing computer activities for nursing home residents with dementia. Non-pharmacological Therapies in Dementia, $3,1-10$.

Wenger, G. C., Scott, A., \& Seddon, D. (2002). The experience of caring for older people with dementia in a rural area: Using services. Aging \& Mental Health, 6, 30-38.

Nyman, S. R., Innes, A., \& Heward, M. (in press). Social care and support needs of community-dwelling people with dementia and concurrent visual impairment. Aging and Mental Health. 
Table 1: Inclusion and exclusion criteria for participation in the study

\begin{tabular}{|c|c|}
\hline Inclusion criteria $^{1}$ & Exclusion criteria $^{2}$ \\
\hline Received a formal diagnosis of dementia, or & Would be distressed by taking part in the \\
\hline had been referred for / were in the process of & interview, as deemed by the recruiting \\
\hline receiving an assessment of dementia. & organisation. \\
\hline Certified as having a visual impairment, & Would pose a risk to the researcher - due to \\
\hline registered blind or partially sighted, or who & the nature of their condition or their personal \\
\hline self-reported low vision ${ }^{3}$. & circumstances - as deemed by the recruiting \\
\hline
\end{tabular}

Community-dwelling, including mainstream Living in a residential care or hospital (or 'general needs') housing, sheltered setting. housing ${ }^{4}$, and extra care housing ${ }^{5}$.

Lacked capacity to give informed consent as defined by the Mental Capacity Act (2005).

\footnotetext{
${ }^{1}$ For inclusion, participants had to meet all three criteria.

${ }^{2}$ For exclusion, participants only had to meet one criterion.

${ }^{3}$ We included participants who experienced visual dysfunction whether caused by ocular disease (e.g. macular disease) or by dementia (due to damage to areas of the brain responsible for interpretation of visual images), as the focus of our study was on the lived experience of visual dysfunction and dementia, regardless of underlying cause. This meant that those with e.g. posterior cortical atrophy who only had dementia (and not visual impairment caused by ocular disease) were still able to participate in the study due to still experiencing visual dysfunction.
}

Nyman, S. R., Innes, A., \& Heward, M. (in press). Social care and support needs of community-dwelling people with dementia and concurrent visual impairment. Aging and Mental Health. 
${ }^{4}$ Sheltered housing, also known as retirement housing or warden-assisted housing, is designed for older people to live independently; there may be a warden on site, or simply an alarm system and/or visiting warden.

${ }^{5}$ Extra care housing (also known as housing with care, very sheltered housing, or assisted living) is designed with the needs of frailer older people in mind; these schemes differ but generally have a greater range of on-site leisure facilities, sometimes provide meals, and have 24-hour staffing.

Nyman, S. R., Innes, A., \& Heward, M. (in press). Social care and support needs of community-dwelling people with dementia and concurrent visual impairment. Aging and Mental Health. 
Table 2: Demographic details of participants with dementia and concurrent visual impairment

\begin{tabular}{ll}
\hline Variable & Frequency $(\mathrm{N}=26)$
\end{tabular}

Gender

Female

Male

9

Housing type

Flat

House

Bungalow

Housing situation

Mainstream: Owner-occupation

Mainstream: Social renting

Sheltered housing (managed by social landlord)

2

Extra care (managed by social landlord)

Occupancy

Living alone

Lives with spouse / partner

Other

Visual impairment diagnosis

Macular degeneration

Cataracts

Glaucoma and one other condition ${ }^{1} \quad 3$

Unconfirmed at interview 3

Dementia-related $^{2}$ 2

Other

Nyman, S. R., Innes, A., \& Heward, M. (in press). Social care and support needs of community-dwelling people with dementia and concurrent visual impairment. Aging and Mental Health. 
Years since onset of visual impairment

1 year or less

2-5 years

6-10 years

Over 10 years

Unconfirmed at interview

Dementia diagnosis

No formal diagnosis $\quad 8$

Has dementia but could not confirm which type 8

Alzheimer's disease $\quad 4$

Vascular dementia ${ }^{3}$

Posterior Cortical Atrophy 1

Mixed dementia (Alzheimer's and vascular) 1

Years since diagnosed with dementia / experienced memory problems

1 year or less 7

$\begin{array}{ll}2-5 \text { years } & 7\end{array}$

6-10 years 3

Over 10 years 1

Unconfirmed at interview $\quad 8$

${ }^{\mathrm{T}} \mathrm{x} 1$ glaucoma and cataracts, $\mathrm{x} 1$ glaucoma and macular degeneration, and $\mathrm{x} 1$ glaucoma and damaged retina.

${ }^{2}$ In both cases, the symptoms of dementia interfered with perception (interpretation of the visual field). In one case the type of dementia was diagnosed as posterior cortical atrophy. ${ }^{3}$ One participant did not provide the term vascular dementia but stated they had memory loss as a consequence of a recent stroke.

Nyman, S. R., Innes, A., \& Heward, M. (in press). Social care and support needs of community-dwelling people with dementia and concurrent visual impairment. Aging and Mental Health. 